\title{
ANÁLISE DAS ÁREAS SUSCETÍVEIS A INUNDAÇÕES NA BACIA DO RIO FORQUILHAS, SÃO JOSÉ/SC
}

\author{
Francielle da Silva Cardozo* \\ Maria Lúcia de Paula Herrmann** \\ Gabriel Pereira**
}

\section{RESUMO:}

O presente trabalho tem como objetivo principal analisar as áreas suscetíveis a inundações da bacia do rio Forquilhas, localizada no município de São José, Santa Catarina. Entrevistas concedidas pelos moradores da área de estudo a respeito das marcas de água foram utilizadas para determinar a altura das inundações, sendo posteriormente inseridas no mapa planialtimétrico, com curvas de nível a cada metro, sendo que o mapa final foi dividido em 5 classes de suscetibilidade (muito baixa, baixa, média, alta e muito alta). Assim, os resultados das análises mostram que a área inundável da bacia do rio Forquilhas é de aproximadamente $6 \mathrm{~km}^{2}$, abrangendo 1.576 domicílios e 5.515 residentes, espacialmente distribuídos pelas diferentes classes de suscetibilidade, representando $17,67 \%$ do total da área de estudo e $20,25 \%$ da população total.

\section{PALAVRAS-CHAVE:}

Desastres Naturais; Áreas Suscetíveis a Inundações; bacia do rio Forquilhas; Expansão Urbana; Impactos Ambientais.

\section{ABSTRACT:}

The main objective of this work is to analyze the susceptible areas of floods of the Forquilhas river basin, located in São José, Santa Catarina State. Interviews given by the residents of the study area about the water traces were used to determine the height of the floods, and were subsequently inserted in the planialtimetric map, with curves at 1 meter each, where the final map was divided into 5 classes of susceptibility (very low, low, medium, high and very high). Therefore, the analysis results show that the floodplain of the Forquilhas river basin is approximately $6 \mathrm{~km}^{2}$, covering 1.576 houses and 5.515 residents, spatially distributed in the different classes of susceptibility, representing $17,67 \%$ of the total study area and $20,25 \%$ of the total population.

\section{KEY-WORDS:}

Natural Disasters; Susceptible areas of floods; Forquilhas river basin; Urban Expansion; Environmental Impacts.

\section{Introdução}

O processo de expansão urbana que se intensificou no Brasil em meados da década de 70 acarretou a ocupação de áreas de risco, tais como as zonas de encostas declivosas e de planícies de inundação. Essas ocupações ocorreram muitas vezes sem infraestruturas adequadas e ocasionaram degradações ambientais, dentre as quais pode-se citar o desmatamento de encostas, a impermeabilização do solo, a retilinização de canais, a supressão da mata ciliar, o aterro em áreas de mangues e banhados, entre outras. Aliado ao crescimento urbano, outros fatores peculiares do Estado de Santa Catarina auxiliam no aumento da incidência 
das inundações, como os altos índices pluviométricos que ocorrem durante $o$ ano.

O Estado de Santa Catarina merece destaque e atenção especial no que se refere à ocorrência de eventos naturais extremos, principalmente decorrentes das fortes chuvas. A região Sul do Brasil é uma área de passagem de frentes frias em frontogênese, o que proporciona mudanças bruscas de tempo e notáveis desvios pluviométricos anuais. Nas estações de primavera e verão, os índices pluviométricos vinculam-se aos sistemas de frentes estacionárias e processos convectivos, durante as estações de outono e inverno, os sistemas frontais e os vórtices ciclônicos podem provocar chuvas violentas ao longo de toda a costa, que consequentemente agravam-se com o efeito orográfico (HERRMANN et al., 2005). O Estado de Santa Catarina também é afetado por episódios pluviais irregulares decorrentes do fenômeno El Niño que provoca, em determinadas circunstâncias, chuvas intensas.

O processo de expansão urbana no município de São José foi originado pela proposta do governo do Estado na década de 60, a partir da criação de conjuntos habitacionais para a população de baixa renda, disponibilizados para suprir a demanda do uso residencial, ainda que determinados locais não fossem propícios à moradia. O crescimento urbano nessa época também esteve ligado à implantação da BR-101, que propiciou a abertura de loteamentos perpendiculares à rodovia, maior circulação de mercadorias e expansão do comércio local (HERRMANN, 1999).

De acordo com o levantamento dos desastres naturais no Estado de Santa Catarina (HERRMANN et al., 2005), e com a atualização até o ano de 2008, ocorreram no município de São José 23 episódios de inundações bruscas e 10 de inundações graduais, representando um dos municípios mais impactados pelos desastres naturais, com um total de 44 ocorrências ao longo de 28 anos.

As inundações graduais ocorrem quando a água eleva-se de forma lenta e previsível, mantendo-se em situação de cheia durante algum tempo, e a seguir escoando-se gradualmente.
Como exemplos delas incluem-se as inundações dos rios Amazonas, Nilo e Mississipi. Este tipo de inundação possui uma sazonalidade (periodicidade), e aparentemente não parece ser tão violenta, porém sua área de atuação é extensa. Por outro lado, popularmente conhecida como enxurrada, a inundação brusca é originada devido à ocorrência de precipitações intensas e concentradas, principalmente em regiões de relevo acidentado, nas quais a elevação dos caudais é súbita e o seu escoamento é violento. Esse tipo de inundação ocorre em um tempo próximo ao evento da chuva que a causa e a elevação das águas é repentina, porém a área de impacto é bem menor do que as áreas das inundações graduais (CASTRO, 2003).

Para Herrmann et al. (2005) a inundação gradual é o tipo de desastre natural que mais ocorre em todo o Estado de Santa Catarina, causando sérios impactos socioeconômicos. A frequência dos eventos mais severos está diretamente associada aos anos de El Niño, que atua com mais intensidade no inverno na Região Sul do Brasil, provocando episódios pluviais intensos. Dentre as áreas mais suscetíveis, destacam-se as regiões costeiras, em virtude do relevo plano e do adensamento populacional.

Em Santa Catarina, as inundações bruscas já causaram sérios danos e prejuízos, principalmente a partir da década de $90 \mathrm{com}$ a intensificação do processo de urbanização. A maior frequência foi registrada no verão, principalmente nos meses de janeiro e fevereiro devido às fortes convecções tropicais. O fenômeno é o resultado da interação de diversos processos atmosféricos e terrestres, como a ocorrência de precipitações extremas, a umidade no solo (precipitação antecedente), a forma das encostas, relevos íngremes, as superfícies impermeáveis (calçamentos, arruamentos, etc.) e a repentina descarga d'água (rompimento de barragens, açudes, etc.). Em alguns casos, todos estes pressupostos podem estar presentes, o que eleva ao máximo o poder de destruição do fenômeno (MARCELINO e GOERL, 2005).

O município de São José, principalmente a área de estudo, possui características físicas 
que limitam as ocupações urbanas, apresentando muitas áreas suscetíveis a inundações, originadas principalmente por episódios pluviais intensos. Sendo assim, o objetivo deste trabalho é analisar as áreas suscetíveis a inundações da bacia do rio Forquilhas, pois a mesma é frequentemente submetida a desastres, provocando impactos ambientais e socioeconômicos. O mapeamento dessas áreas poderá fornecer importantes informações para elaboração de Planos de Ações Preventivas à ocupação humana em áreas de riscos, ou seja, adotando medidas que auxiliem no direcionamento das ocupações para locais adequados, evitando perdas de vidas e de bens materiais.

\section{Localização e Caracterização dos Aspectos Naturais da Área de Estudo}

A bacia do rio Forquilhas (figura 1) faz parte da vertente do Atlântico e está situada integralmente no município de São José, nos paralelos $27^{\circ} 31^{\prime} / 27^{\circ} 35^{\prime}$ de latitude Sul e entre os meridianos $48^{\circ} 38^{\prime} / 48^{\circ} 44^{\prime}$ de Longitude Oeste. O rio Forquilhas é afluente do rio Maruim pela margem esquerda e se desenvolve no sentido geral Noroeste-Sudeste. Possui extensão de 12 $\mathrm{km}$ (quilômetros), apresentando uma área de $52,47 \mathrm{~km}^{2}$ (quilômetros quadrados) e representa o principal sistema de drenagem que banha o município de São José.

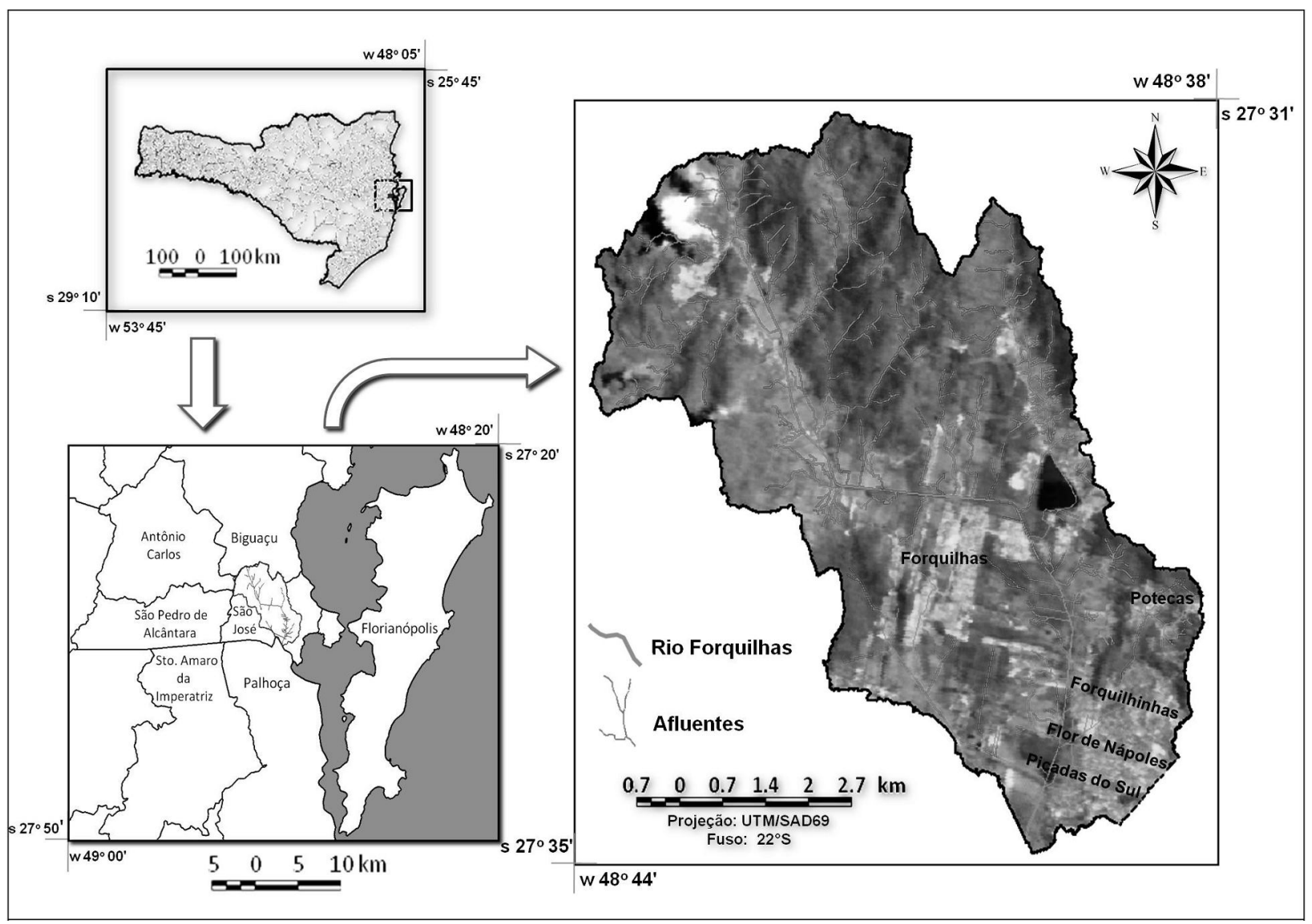

Figura 1: Localização da área de estudo. 
A área de estudo insere-se em dois tipos de Domínios Morfoestruturais: o Embasamento Cristalino, formado por rochas metamórficas, por granitos e diabásios; e a Cobertura Sedimentar Quaternária, constituída principalmente por depósitos inconsolidados ou fracamente consolidados de areias, silte, argila e conglomerado (FERREIRA, 1994). A geologia da área de estudo é caracterizada por seis unidades litoestratigráficas: a Suíte Intrusiva São Pedro de Alcântara, a Suíte Intrusiva Pedras Grandes e o Complexo Granito-Gnáissico, inseridos no Domínio do Embasamento Cristalino; e os Depósitos Aluvionares, os Depósitos Colúvio-Alúvio-Eluviais e os Depósitos Síltico-argilosos de Baias e Lagunas, inseridos no Domínio da Cobertura Sedimentar Quaternária (PIRES et al., 1995; PIRES, 2000). A geomorfologia da bacia do rio Forquilhas é destacada pelas elevações rochosas da unidade geomorfológica Serras do Leste Catarinense e pelas áreas sedimentares planas da unidade geomorfológica Planícies Costeiras. Na Unidade Geomorfológica Serras do Leste Catarinense, estão inseridos os Modelados de Dissecação em Montanha, Modelado de Dissecação em Outeiro (Morraria) e Modelado de Dissecação em Colina. Na Unidade Geomorfológica Planícies Costeiras estão inseridos os Modelados de Acumulação Planície Flúvio-Marinha, Modelado de Acumulação Terraço Fluvial e Modelado de Acumulação Rampas Colúvio-Eluviais (HERRMANN \& ROSA, 1991; FERREIRA, 1994; HERRMANN, 1999).

Segundo o IBGE (2004), seguindo a classificação proposta pela EMBRAPA (1999), ocorrem na área de estudo quatro tipos de solos, o ARGISSOLO VERMELHO-AMARELO Distrófico, O CAMBISSOLO HÁPLICO Tb Distrófico, o CAMBISSOLO FLÚVICO Tb Distrófico e o GLEISSOLO HÁPLICO Tb Distrófico. A bacia do rio Forquilhas faz parte do sistema da vertente Atlântica, que drena para o litoral, onde os rios possuem características de menor caudal e possuem perfil longitudinal acidentado, apresentando em seu curso cascatas e corredeiras nas partes elevadas e meandros nas áreas com baixos valores hipsométricos (SANTA CATARINA, 1997).

A área de estudo está inserida, segundo os critérios de Strahler (1965), no grupo de Climas Controlados por Massas de Ar Tropicais e Polares e mais diretamente ao tipo dos Climas Úmidos das Porções Orientais e Subtropicais dos Continentes Dominados Largamente por Massas Tropicais Marítimicas (MONTEIRO, 1968). No litoral, a Massa Polar Atlântica (mPa), a Frente Polar Atlântica (FPA) e a Massa Tropical Atlântica ( $\mathrm{mTa}$ ) alternam-se durante todo o ano, predominando a mTa. A FPA atua principalmente no inverno, recuando para o extremo sul do continente no verão, e as massas Equatorial Continental (mEc) e Tropical Continental (mTc) aparecem no verão. Também existem na região Sul outros sistemas que modificam significativamente as condições de tempo, entre eles, o vórtice ciclônico (VC), o Jato Subtropical (JTS) em altos níveis, os Complexos Convectivos de Mesoescala (CCM's), e em épocas alternadas, ocorre o fenômeno $E l$ Niño-Oscilação Sul (ENOS), que pode influenciar o tempo de uma região em sua fase positiva (EL Niño) e em sua fase negativa (La Niña), ocasionando o aumento da precipitação e da estiagem, respectivamente.

A vegetação da área de estudo é composta pela Região da Floresta Ombrófila Densa (Mata Atlântica), que se estende ao longo da costa Atlântica, ocupando as planícies Cenozóicas do litoral, bem como as encostas da Serra Geral, subdividida em Floresta Ombrófila Densa Montana, em Floresta Ombrófila Densa Submontana e em Floresta Ombrófila Densa das Terras Baixas (FERREIRA, 1994; COELHO NETO, 1995). Com o passar do tempo, essas florestas foram sendo derrubadas para dar origem à povoamentos, áreas agrícolas e pastagens (HARO, 1996). Devido aos desmatamentos, a floresta primária da região de estudo praticamente desapareceu, dando lugar a uma sucessão ecológica, que se inicia pela fase pioneira, passando para a capoeirinha, capoeira e por fim o capoeirão (VEADO, 1999). 


\section{Materiais e Métodos}

Para a elaboração do mapa das áreas suscetíveis a inundações obteve-se como referência o trabalho realizado por Hermann et al. (2000) e Herrmann e Cardozo (2008), que determinaram a altura das inundações dos bairros da área de estudo, considerando as respostas dadas a respeito das marcas da água coletadas durante a aplicação de 100 questionários entre os moradores da bacia do rio Forquilhas. Desta forma, as diferentes alturas das inundações foram inseridas no mapa planialtimétrico, com curvas de nível a cada 1 metro, e, então, foi realizado um novo mapeamento em outros locais da bacia com cotas superiores a 5 metros, com a finalidade de identificar outras possíveis áreas inundáveis.

Posteriormente, as diferentes classes de inundações foram digitalizadas como polígonos fechados no programa SPRING, desenvolvido pelo Instituto Nacional de Pesquisas Espaciais (INPE), no qual o nível hierárquico final das alturas das inundações foi delimitado em muito alto (cota 0 a 1 ), alto (cota 1 a 2 ), médio ( $\operatorname{cota} 2$ a 3 ), baixo (cota 3 a 4) e muito baixo (cota 4 a 8 ). A edição final foi realizada inserindo-se a hidrografia e os polígonos das construções presentes na área de estudo. Com base no censo socioeconômico do IBGE (2000) determinou-se o número de residências e de pessoas inseridas em cada classe de inundações.

\section{Resultados}

Os problemas relacionados às inundações são muito significativos, pois inúmeras cidades desenvolveram suas malhas urbanas ao longo dos leitos dos rios, colocando assim a população em risco. As inundações são fenômenos naturais que ocorrem devido às precipitações intensas, porém elas se intensificam como desastre natural quando existem interferências antropogênicas, como, por exemplo, a impermeabilização do solo, o desmatamento, a agricultura e a pecuária nas encostas dos morros e nas margens ribeirinhas.

Estas práticas impedem ou dificultam a infiltração das águas no subsolo fazendo com que escoem diretamente para os canais fluviais, ocasionando perdas de solo e aumento da vazão dos rios. As instalações urbanas também acentuam a gravidade das inundações, como os loteamentos residenciais e sistemas viários instalados nas planícies aluviais sujeitas às inundações, bem como as obras de engenharia (canalizações e retificações de canais, comportas e barragens) que interferem no ciclo hidrológico.

Muitos desses fatos podem ser observados na área de estudo, pois existem ocupações urbanas instaladas na planície de inundação do rio Forquilhas, próximas aos canais fluviais. Ainda, foram realizadas obras de engenharia no local de estudo, pois o rio Forquilhas, nas áreas planas de seu baixo curso, teve grande parte de seu leito retificado mediante canalizações na década de 60 pelo extinto Departamento Nacional de Obras de Saneamento (DNOS) para diminuir o risco das inundações e para a expansão do sítio urbano (FERREIRA, 1994). Assim como a retificação, é possível verificar que a grande maioria de seus afluentes encontra-se canalizado, principalmente na área urbanizada. Ou seja, a incapacidade temporária dos canais de drenagem suportarem o volume de água que recebem é na maioria das vezes ocasionada pelas interferências humanas, como os aterros, a construção de estradas e edificações que originam as impermeabilizações, além das retificações dos canais, como pode ser observado no baixo curso do Rio Forquilhas.

A figura 2 mostra as áreas suscetíveis às inundações na bacia do rio Forquilhas, inseridas na Unidade Geomorfológica Planícies Costeiras, classificadas em muito baixa, baixa, média, alta e muito alta, de acordo com os diferentes graus de suscetibilidade.

As áreas suscetíveis às inundações muito baixas correspondem ao setor do médio vale da bacia, localizadas no modelado de acumulação terraço fluvial, margeando o início do modelado de acumulação rampas colúvio-eluviais. A inundação atinge o seu máximo até a cota de 8 metros, possuindo área de $1,47 \mathrm{Km}^{2}$, e nesse setor a altura da água atinge entre $0,20 \mathrm{~cm}$ e $0,80 \mathrm{~cm}$. Parte dos bairros de Forquilhas e Potecas estão localizados nessa classe de inundação, e 


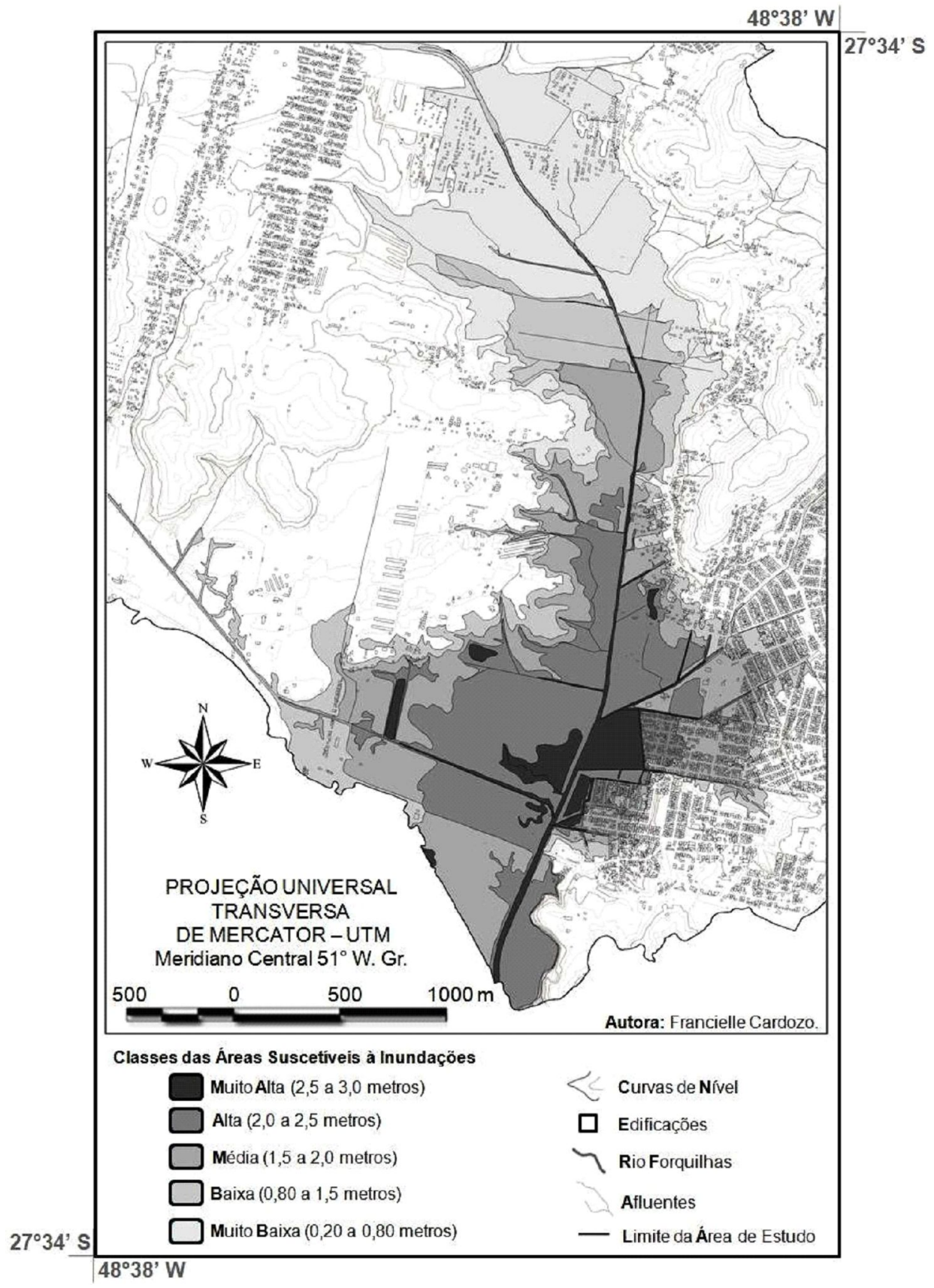

Figura 2: Mapa das áreas suscetíveis às inundações e a mancha de urbanização presente na bacia do rio Forquilhas. 
apesar do rio Forquilhas também se encontrar próximo, nesse trecho ele encontra-se bem encaixado, sendo assim, ele não é o responsável pelas inundações que ocorrem nesse setor, pois quando ocorrem períodos de precipitação muito intensos, a água não chega a ultrapassar 0,20 cm. Nessa área, os responsáveis pelas inundações são os canais que se encontram por todo o local, principalmente devido ao mal planejamento com que são feitas as obras de engenharia, realizadas sem a infraestrutura adequada, destacando-se a construção de estradas e a colocação de tubulações de maneira inadequada sobre esses canais que, eventualmente, não suportam o volume de água originada em dias de precipitações intensas, conforme figura $3(A, B$ e $C)$.
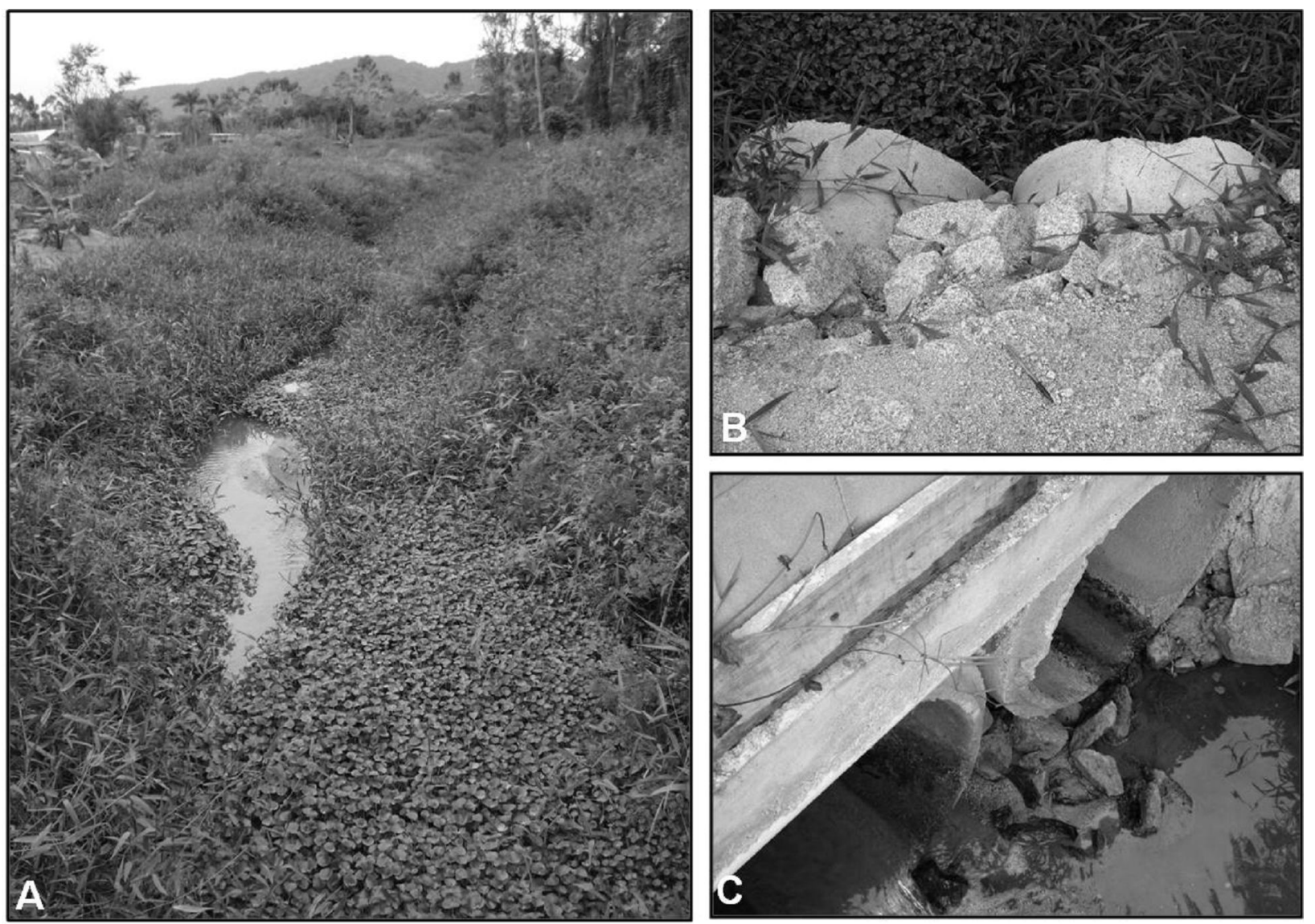

Figura 3: A) Detalhe de um dos vários canais presentes no setor de suscetibilidade muito baixa às inundações, bairro Forquilhas. B) Tipo de tubulação que foi colocada para escoar as águas que passam pelos canais. C) Maior detalhe da tubulação.

Outro fator que contribui para a intensificação das inundações na área de estudo foi a construção da BR-101, da SC-407 e de estradas municipais, que em épocas de fortes chuvas, funcionam para a área como um dique, devido ao aterro realizado para a elevação das pistas, principalmente quando essas chuvas associam-se com períodos de maré alta, pois a 
mesma age como represador do escoamento da água na foz, aumentando ainda mais o problema. Além disso, ressaltam-se as inúmeras pontes baixas de concreto presentes na malha viária do local de estudo, que acabam funcionando como barragens em dias de chuva (FERREIRA, 1994).

As áreas suscetíveis às inundações classificadas como baixa encontram-se inseridas no modelado de acumulação flúvio-marinha, entre as cotas 4 e 5 metros, possuindo $1,10 \mathrm{Km}^{2}$ de extensão, sendo que a altura das águas atinge entre $0,80 \mathrm{~cm}$ e 1,5 metros. Nessa classe estão localizados parte dos bairros de Potecas, Forquilhinhas, Flor de Nápoles, Picadas do Sul e Sertão do Maruim. Além da grande quantidade de canais existentes, o rio Forquilhas já possui grande influência para ocasionar as inundações, pois esses bairros encontram-se inseridos em áreas mais planas. A criação desses bairros foi estimulada pela construção de um grande loteamento da Companhia de Habitação do Estado de Santa Catarina (COHAB/SC) na década de 60, incentivados pela criação do Distrito Industrial e pela proximidade da BR-101. Após a implantação do conjunto habitacional da COHAB/SC, o setor privado passou a se interessar pela área e construiu loteamentos para pessoas de baixo poder aquisitivo, não se responsabilizando pela infraestrutura, os quais foram cadastrados pela

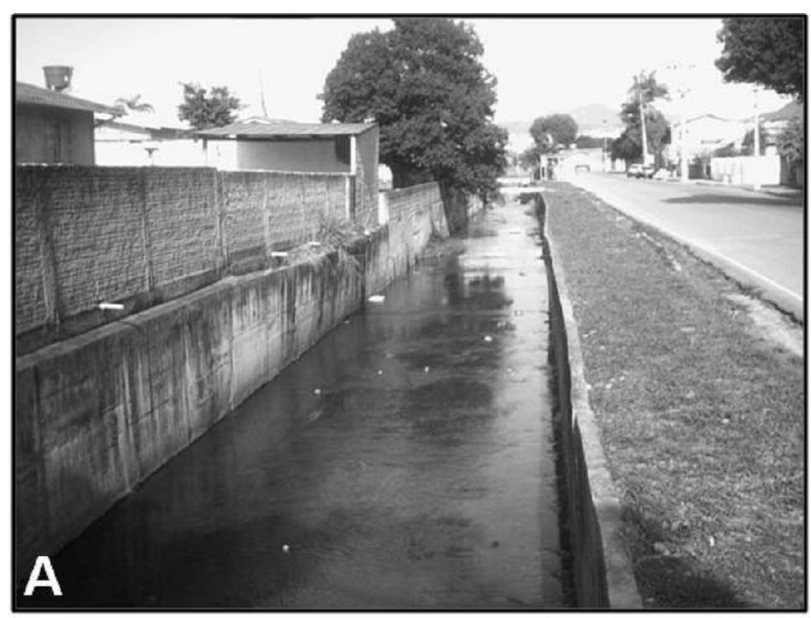

prefeitura mesmo estando inseridos em uma área historicamente atingida pelas inundações (FERREIRA, 1994). Ainda segundo a autora, para que o bairro Flor de Nápoles pudesse ser implantado em 1979, a autorização estava condicionada pela Secretaria de Obras à colocação de um aterro de dois metros de altura que assegurava a proteção contra a inundação do local, porém o parecer técnico foi desconsiderado pelo governo local da época, que aprovou o loteamento sem as medidas de segurança. Ainda, as inundações que ocorrem nesse setor não se devem somente à inserção da população em locais não propícios e de riscos, mas também às modificações feitas nos meios naturais, como as alterações realizadas no rio Forquilhas e nos seus afluentes.

O rio Forquilhas teve grande parte de seu leito retificado e muitos de seus afluentes foram canalizados na década de 60 pelo extinto DNOS, conforme figura 4 ( $A$ e $B$ ). A situação se agrava quando essas obras são mal estruturadas e dimensionadas, e quando ocorre o rompimento de barragens e o acúmulo de lixos e entulhos nos canais fluviais, acentuando o trasbordamento (HERRMANN et al., 2005). Em geral, a retificação e a canalização possuem o objetivo de diminuir ou acabar com o problema das inundações, porém, essas obras são realizadas subestimando a intensidade com que ocorrem as precipitações,

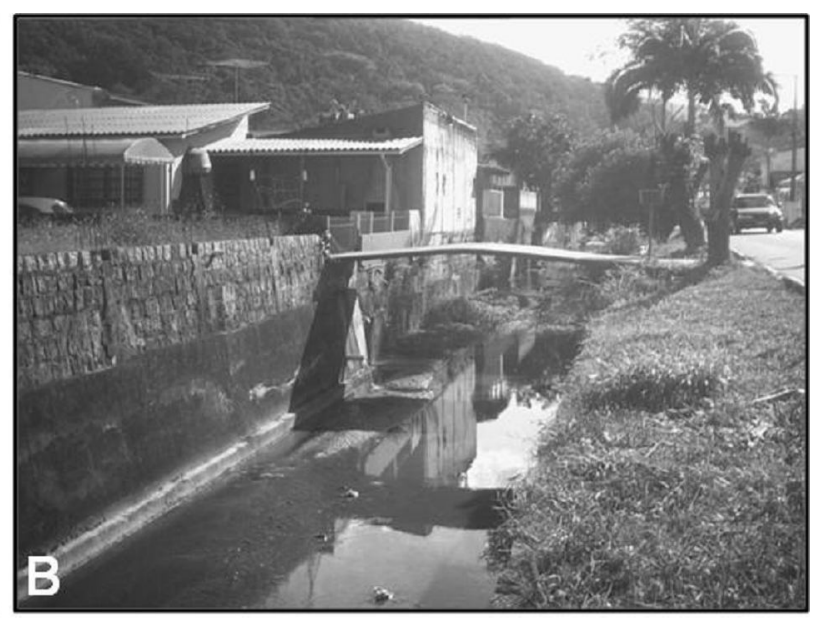

Figura 4: A e B) Detalhe de dois dos vários canais que se encontram canalizados na área de estudo, bairro Forquilhinhas. 
principalmente em períodos de precipitações acentuadas aliadas à maré alta. Ainda, a utilização desse tipo de obra de engenharia é controversa, pois o aprofundamento do canal promove o abaixamento do nível de base, favorecendo a retomada erosiva nos afluentes, mudando o padrão de drenagem, reduzindo o comprimento do canal com a perda dos meandros, alterando a forma do canal, diminuindo a rugosidade do leito e aumentando o seu gradiente (CUNHA, 1994).

A mudança no traçado do rio Forquilhas propiciou o aumento do gradiente no perfil longitudinal devido à aceleração erosiva, provocando o aprofundamento e o alargamento do talvegue. Essas obras de retificação alteraram a dinâmica fluvial e provocaram um aumento considerável do transporte de sedimentos e lixos, tornando-se necessárias constantes dragagens para favorecer o escoamento rápido das águas e evitar a obstrução dos canais, e, consequentemente, as inundações (HERRMANN et al., 1994; FERREIRA, 1994). Porém, essas medidas não foram suficientes para conter as cheias, primeiramente, porque as últimas obras de dragagem foram realizadas na década de 90 , período em que ocorreram várias inundações, e em segundo lugar porque, que o problema das inundações na bacia do rio Forquilhas é atual, pois a última grande inundação ocorreu no final de janeiro e novembro de 2008.

Presentes no modelado de acumulação flúvio-marinha, as áreas localizadas entre as cotas 3 e 4 metros foram classificadas como de média suscetibilidade às inundações, abrangendo parte dos bairros de Forquilhinhas, Flor de Nápoles e Picadas do Sul. A altura das águas atinge valores entre 1,5 e 2,0 metros, possuindo essa classe uma área total de $1,32 \mathrm{Km}^{2}$. Do mesmo modo, os problemas das inundações que ocorrem nesse setor originam-se dos mesmos ocorridos nas áreas de suscetibilidade baixa. A figura 5 (A) mostra um afluente do rio Forquilhas, localizado no loteamento Jardim das Palmeiras, no bairro Forquilhinhas. Como se pode notar, ele ainda se encontra preservado em sua forma natural, encaixado em uma área de encosta, onde a água possui grande velocidade, chegando a apresentar pequenas corredeiras, denotando que em períodos de grande precipitação a velocidade da água aumenta ainda mais. A jusante dessa área, esse afluente encontra-se canalizado, de acordo com a figura 5 (B), denotando o problema que existe na realização de canalizações que não conseguem suportar a velocidade e o volume das águas, acabando por inundar as áreas próximas.
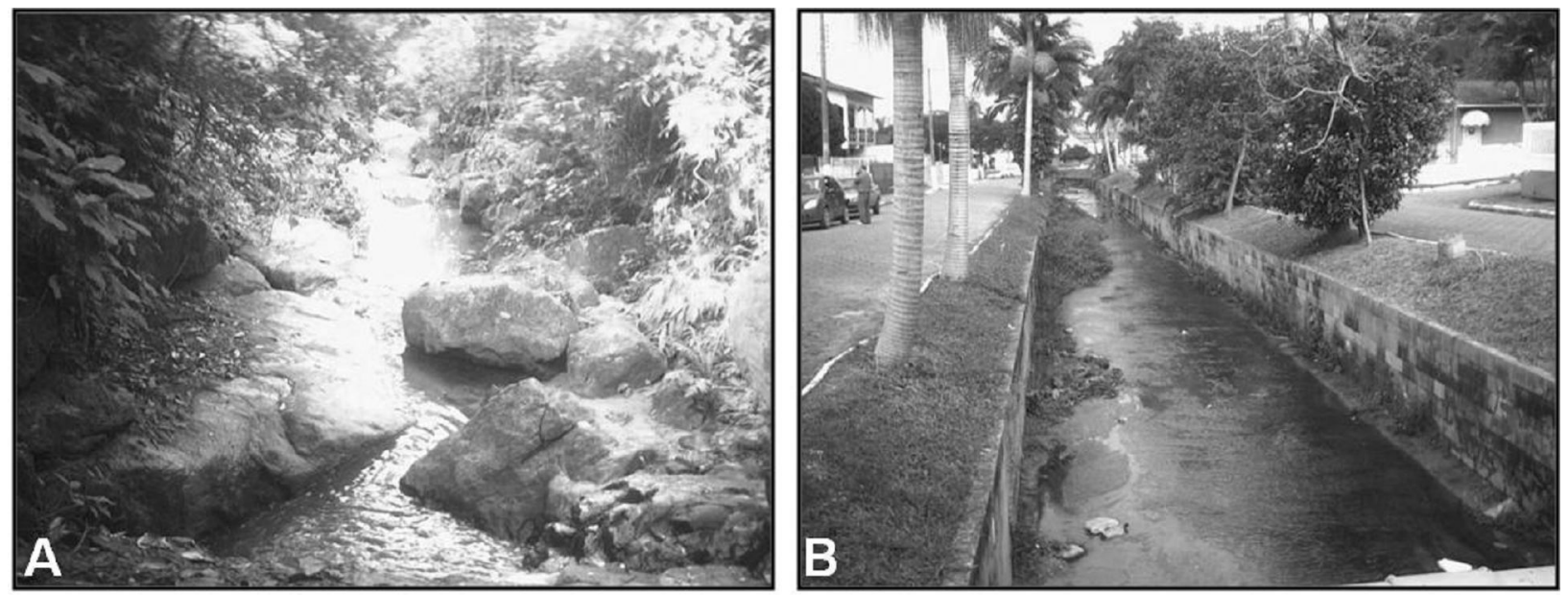

Figura 5: A) Afluente do rio Forquilhas, bairro Forquilhinhas.

B) Mesmo afluente em área à jusante, já canalizado. 
As áreas de alta suscetibilidade a inundação, representadas pelas cotas de 2 a 3 metros, abrangem $1,33 \mathrm{~km}^{2}$. A altura das águas nesse setor pode atingir entre $2,0 \mathrm{e}$ 3,0 metros. Essa classe encontra-se presente no modelado de acumulação flúvio-marinha, apresentando uma suscetibilidade alta devido à existência dos fatores já expostos que podem acarretar inundações, como a impermeabilização do solo provocada pela intensa urbanização e as alterações dos cursos d'água naturais. Nessa área os moradores costumam adotar as chamadas medidas estruturais, prevenindo-se de futuras inundações ao colocar suas casas sobre aterros, ou construindo suas casas sobre pilotis, conforme figura 6 ( $A$ e $B$ ). Os moradores dessa área em particular não são afetados somente pelas inundações, mas também por constantes alagamentos que ocorrem em dias de precipitações mais fortes. O problema maior concentra-se nas casas que não possuem suas construções sobre pilotis, pois, segundo relato de moradores, as alturas das águas nas inundações da década de 1990 atingiram até o teto de algumas casas.
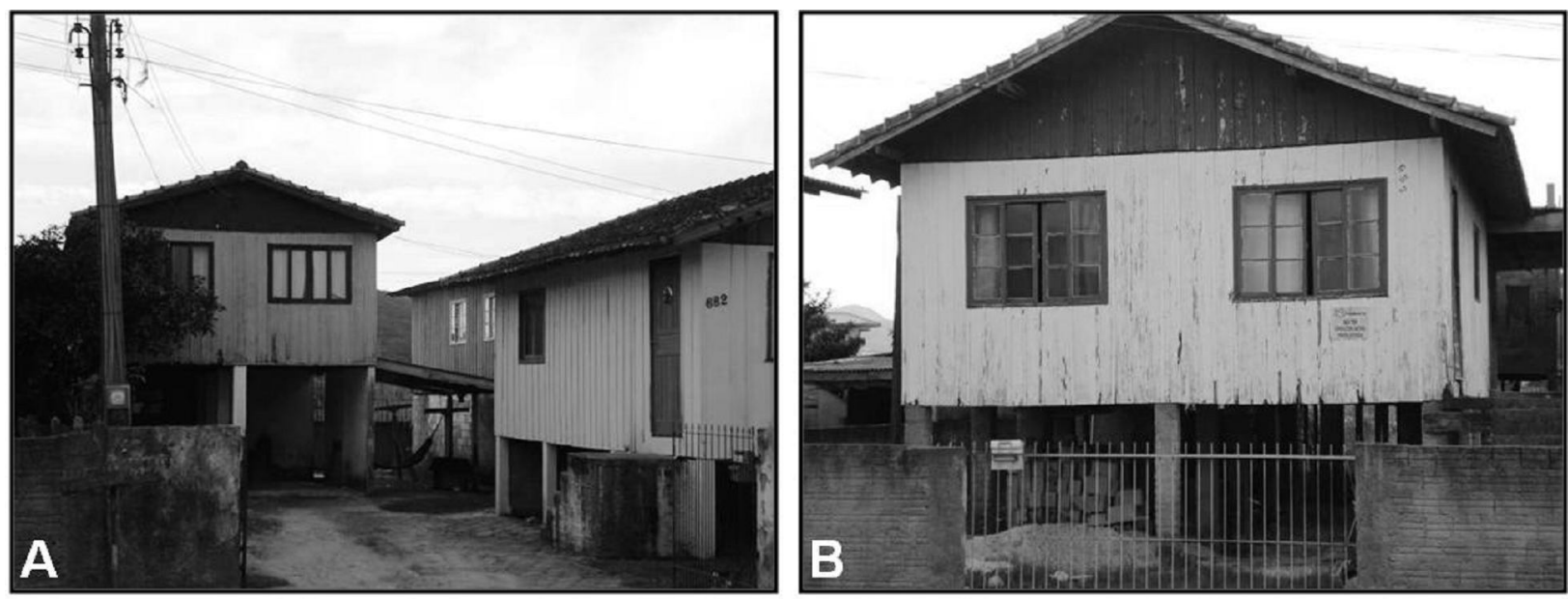

Figura 6: A e B) Casas construídas sobre pilotis para prevenir as inundações, bairro Flor de Nápoles.

As áreas classificadas como de suscetibilidade muito alta às inundações encontram-se no modelado de acumulação flúviomarinha, nas cotas que vão de 1,0 a 2,0 metros, possuindo $0,28 \mathrm{Km}^{2}$ de extensão. Parte dos bairros de Flor de Nápoles e Picadas do Sul se localizam próximos a essa classe, e a altura que a água pode atingir nesse setor é superior aos 3,0 metros. Embora a base cartográfica adquirida na Prefeitura de São José, utilizada para fazer a contagem das casas inseridas nas áreas inundáveis, não apresentem residências, Herrmann et al. (2002) e Herrmann e Cardozo (2008) verificaram que podem ser encontradas algumas casas presentes dentro dessa classe, pois muitas ruas desses bairros foram abertas até chegar ao limite dos canais, no qual a distância das casas com os mesmos ficou situada em torno de 2 metros, sendo que algumas pessoas acabaram inserindo suas casas além dessa cota, ficando presentes dentro da área de suscetibilidade muito alta.

De acordo com o censo do IBGE (2000), o número de domicílios particulares permanentes é de 892 no bairro de Flor de Nápoles, 2.115 em Forquilhas, 3.212 em Forquilhinhas, $1.006 \mathrm{em}$ Picadas do Sul, 859 em Potecas e 835 no Sertão do Maruim. Dividindo-se o número total de habitantes pelo número de domicílios permanentes, obtêm-se uma média de 3,50 pessoas em cada residência. Considerando que os bairros encontram-se parcialmente inseridos nas áreas suscetíveis a inundações, deve-se, 
portanto, salientar que apenas uma parcela do total dos domicílios é afetada pelas inundações.

De acordo com o resultado final, o setor que abrange a classe de suscetibilidade muito baixa a inundações possui 194 residências, abrangendo aproximadamente 700 pessoas, onde se localizam parte dos bairros de Forquilhas e Potecas. O setor que engloba a classe de suscetibilidade baixa abrange parte dos bairros de Potecas, Forquilhinhas, Flor de Nápoles, Picadas do Sul e Sertão do Maruim, totalizando 493 residências e aproximadamente 1.750 pessoas. A classe de suscetibilidade média a inundação abrange parte dos bairros de Forquilhinhas, Flor de Nápoles e Picadas do Sul, sendo o setor no qual está inserido o maior número de residências, com 638 e aproximadamente 2.300 pessoas.

A classe de suscetibilidade alta a inundação também abrange os bairros localizados na classe de suscetibilidade média, porém com um número menor, possuindo 251 residências e aproximadamente 900 pessoas. De acordo com a base cartográfica utilizada para o estudo, a classe de suscetibilidade muito alta não possui nenhuma residência fixada nesse setor, porém, como já foi exposto anteriormente, podem-se encontrar algumas residências inseridas nessa classe, nos bairros Flor de Nápoles e Picadas do Sul. Sendo assim, conclui-se que a área inundável presente na bacia do rio Forquilhas é de $5,52 \mathrm{Km}^{2}$, e que de 8.919 domicílios permanentes, 1.576 estão inseridos em áreas suscetíveis a inundações, representando $17,67 \%$ do total da área de estudo, e que de 27.227 habitantes, 5.515 residem em áreas inundáveis, ou seja, 20,25\% da população total.

Durante o período de 1980 a 2008 ocorreram 44 desastres na bacia do rio Forquilhas, sendo que 33 foram decorrentes de inundações, predominando as inundações bruscas com 23 ocorrências e as graduais com 10 ocorrências. Em todos esses episódios, de acordo com os registros disponíveis na Defesa Civil do Estado, as inundações desabrigaram 6.719 pessoas e provocaram 2 vítimas fatais, e em associação com os escorregamentos, os números de desabrigados e mortos foram de 4.279 e 2 respectivamente.

A maioria dos casos de inundações na bacia do rio Forquilhas foi originada durante episódios pluviais intensos devido à passagem de frentes frias, sendo que alguns episódios de calamidade pública ocorreram devido à associação com o fenômeno El Niño. Na área de estudo os episódios de inundação ocorreram em todos os meses do ano, exceto no mês de abril e junho, sendo que a maior frequência ocorreu no verão, principalmente nos meses de janeiro, com 8 ocorrências, e fevereiro, março e dezembro com 5 ocorrências. As inundações bruscas são os eventos que mais ocorrem na área de estudo, portanto, o principal fator causador são as precipitações intensas e de curta duração, que resultam no transbordamento dos rios, canais e bueiros, alagando e inundando ruas e residências, e quando somados com períodos em que a maré está alta, aumentando ainda mais as consequências dos desastres.

Tais problemas demonstram a fragilidade do sistema de drenagem não somente diante das precipitações excessivas, às vezes em conjugação com a maré alta, como também, devido à falta de planejamentos e de fiscalização do uso da terra, aliado à carência da limpeza e manutenção dos cursos d'água naturais e artificiais. Vale ressaltar que o número total de inundações foi retirado dos relatórios de danos enviados pela Prefeitura de São José para a Defesa Civil do Estado, onde não constam outros registros que ocorrem na área de estudo, que não são noticiados por não possuírem importância, mas que com certeza causam grandes transtornos e perdas para a população impactada.

Portanto, pode-se concluir que as ocorrências de inundações registradas na bacia do rio Forquilhas possuem como principal condicionante a presença da ação antrópica, pois as construções causam a impermeabilização do solo. Assim também, os desmatamentos originados com a finalidade da expansão urbana impedem a interceptação da precipitação, favorecendo a velocidade de escoamento e os 
processos erosivos, que emitem sedimentos para os cursos d'água, causando o assoreamento e consequentemente as inundações. Por fim, outro fator condicionante das inundações é a realização de obras de infraestrutura, como a retilinização e a canalização das drenagens, que alteram a dinâmica natural dos rios.

\section{Considerações Finais}

A bacia do rio Forquilhas caracteriza-se por possuir uma ampla área de planície sujeita a inundações e alagamentos. As modificações causadas nas planícies pela interferência antrópica contribuem para a ocorrência de inundações e alagamentos durante os períodos chuvosos, ocorrendo principalmente devido a fatores como a impermeabilização do solo através das construções; da canalização e retilinização dos canais fluviais; das ocupações de margens dos cursos d'água e do lançamento de lixos e esgotos para as drenagens.
As inundações e os alagamentos são frequentes na bacia do rio Forquilhas, principalmente nos bairros Picadas do Sul, Flor de Nápoles, Forquilhinhas e Potecas, afetando principalmente as residências localizadas às margens do rio Forquilhas, nas cotas de 1 a 3 metros, no qual as águas atingem até 3 metros de altura. A elaboração do mapa de suscetibilidade a inundações constitui importante instrumento a ser empregado em futuros trabalhos de prevenção e intervenção na bacia do rio Forquilhas. Considerando a intensa ocupação urbana nas áreas de planície, faz-se necessário a realização de trabalhos preventivos para a instalação dessas residências, já que a prevenção é bem menos onerosa aos cofres públicos do que as medidas corretivas ou de eliminação do problema já instalado. O Poder Público precisa criar meios de garantir as condições básicas de infraestrutura e segurança à população residente em situação de perigo, evitando perdas materiais e de vidas humanas.

\section{Referências Bibliográficas}

CASTRO, A. L. C. Manual de Desastres: desastres naturais. Brasília: Ministério da Integração Nacional, 2003, 174 p.

COELHO NeTO, A. B. Projeto Gerenciamento Costeiro, 2a Fase; Síntese Temática - Vegetação. Florianópolis, IBGE/DIGEO-SUL, 1995.

CUNHA, S. B. Geomorfologia Fluvial. In: GUERRA, A. J. T.; CUNHA, S. B. Geomorfologia: uma atualização de bases e conceitos. Rio de Janeiro: Bertrand Brasil, 1994, 458 p.

FERREIRA, R. C. S. Bacia do Rio Maruim: Transformações e Impactos Ambientais. Florianópolis, 1994, 153 p. Dissertação (Mestrado em Geografia). Universidade Federal de Santa Catarina.

HARO, Martins Afonso Palma de. (org.). Ilha de Santa Catarina: relato dos viajantes estrangeiros nos séculos XVIII e XIX. Florianópolis: UFSC, Lunardelli, 1996.
HERRMANN, M. L. de P.; ROSA, R. O. Geomorfologia. Mapeamento Temático do Município de Florianópolis. Florianópolis, IPUF, IBGE, 1991, 17p.

HERRMANN, M. L. P.; MENDONÇA, M.; CAMPOS, N. J. São José: Avaliação das Enchentes e Deslizamentos Ocorridos em Novembro de 1991 e Fevereiro de 1994. Revista Geosul, Florianópolis: Ed. da UFSC, nº 16, ano VIII, $2^{\circ}$ semestre. 1994.

HERRMANN, M. L. P. Problemas Geoambientais na Faixa Central do Litoral Catarinense. São Paulo, 1999, 307 p. Tese (Doutorado em Geografia). Departamento de Geografia/FFLCH, Universidade de São Paulo.

(org). Atlas de Desastres Naturais do Estado de Santa Catarina. Florianópolis: IOESC, 2005, $146 \mathrm{p}$.

HERRMANN, M. L. P.; MARCELINO, E. V.; ZABOT, C.; MARTINS, N.; LISBOA, T. H. C.; OLIVEIRA, I. 
P. V.; MEDEIROS, J.; MORENA, M. Alturas das Enchentes na Planície Aluvial do Rio Forquilha e suas Consequências nos Bairros de Flor de Nápoles, Jardim Pinheiros e Forquilhinhas no Município de São José - SC. In: Simpósio Nacional de Geomorfologia, 2000, Campinas. II Simpósio de Geomorfologia: o relevo, a água e o homem, 2000.

HERRMANN, M. L. P.; CARDOZO, F. S. As Inundações no Município de São José-SC e suas Consequências nos Bairros Flor de Nápoles, Jardim Pinheiros e Forquilhinhas na Bacia do Rio Forquilhas. In: VII Simpósio Nacional de Geomorfologia - II Encontro Latino-Americano de Geomorfologia, 2008, Belo Horizonte - MG. Anais do VII Simpósio Nacional de Geomorfologia - II Encontro Latino-Americano de Geomorfologia, 2008.

IBGE. Pedologia. Levantamento de Reconhecimento de Média Intensidade dos Solos. Rio de Janeiro, 2004.

MARCELINO, E. V.; GOERL, R. F. Inundação Brusca. In: HERRMANN, M. L. P. (org). Atlas de Desastres Naturais do Estado de Santa Catarina. Florianópolis: IOESC, 2005, 146 p.
MONTEIRO, C. A. F. Clima. Grande Região Sul. IBGE (org.). Rio de Janeiro: Fundação IBGE (Instituto Brasileiro de Geografia e Estatística), 1968.

PIRES, J. L. O Planejamento das Atividades de Mineração para a Área Conurbada de Florianópolis. Florianópolis, 2000, 150 p. Dissertação (Mestrado em Engenharia Civil). Universidade Federal de Santa Catarina.

PIRES, J. L.; COITINHO, J. B. L.; FREIRE, F. A.; FERNANDES, E. Projeto Gerenciamento Costeiro, 2a Fase; Síntese Temática - Geologia. Florianópolis, IBGE/DIGEO-SUL, 1995.

SANTA CATARINA. SECRETARIA DE ESTADO DO DESENVOLVIMENTO URBANO E MEIO AMBIENTE. Bacias hidrográficas do Estado de Santa Catarina: diagnóstico geral. Florianópolis: Instituto CEPA/ SC, 1997, 1 CD-ROM.

STRAHLER, Arthur N. Introduction to Phisical Geografy. New York: John Wiley e Sons, 1965.

VEADO, R. W. A. Geossistemas do Estado de Santa Catarina. Rio Claro, 1999. Tese (Doutorado em Geografia). IGCE, Universidade Estadual Paulista.

Trabalho enviado em novembro de 2009 Trabalho aceito em abril de 2010 